\title{
The Application of Effective Teaching Theory in Higher Education
}

\author{
Yaoyuan Chen ${ }^{1 *}$ \\ ${ }^{1}$ Hubei Engineering University, Xiaogan, CHINA
}

Received 5 August 2017 • Revised 4 October 2017 • Accepted 13 November 2017

\begin{abstract}
The application of "effective teaching" theory in higher education can be described by four indicators of student development and progress, teaching income, reflective teaching and innovative thinking. Foreign scholars believe that the "effective teaching" theory can promote higher education and has a positive effect to enhance students' learning ability. In China, the application of this theory in higher education is still at the surface stage, the relevant scholars believe that the theory can promote the curriculum reform of higher education. This paper introduces the BBM principle, carries on the structural thinking to the four indexes of the students' development and progress, the teaching income, the reflective teaching and the innovative thinking. It took 100 university students as the survey object, the four indexes were taken as the main variables respectively, and the impact on primary and secondary variables on "effective teaching" theory in the case of higher education were analyzed. During the study, 100 university students were as the data mining, and always remain unchanged, so that the indicator is a major variable, that is, to make the indicator as a self-treatment. Through the discussion of the results of the four groups, it is found that no matter which of the four variables as the main variable, the main variables have a major effect on the application, and the secondary variables have a secondary effect on the application. According to the results, it is concluded that in order to strengthen the application of the theory of "effective teaching" in higher education, it should be under the premise that remaining three indicators unchanged, and strengthen the conclusion of the other indicator. Through this analysis, we deepen the depth of the application of the theory of "effective teaching" in higher education, and contribute to the promotion of higher education level in our country.
\end{abstract}

Keywords: effective teaching, curriculum reform, object consciousness, BBM principle, structural thinking

\section{INTRODUCTION}

\begin{abstract}
"Effective teaching" is a teaching form that is not less than the average level of teaching under the premise of conforming to the positive value of the times and individual (Jiang and Chen, 2016). In recent years, "effective teaching" theory is very extensive in the application of higher education. Among them, the development and progress of students, teaching income, reflective teaching, innovative thinking are important indicators to measure the "effective teaching" theory application in the higher education. The so-called "effective" mainly refers to the specific progress or development of the students after a period of teaching from teacher. If the teaching is not effective, it does not mean that if teachers have finished teaching content or teach seriously, but that if students have learned well (Wang and Zhao, 2016; Cobbinah and Bayaga, 2017). Therefore, whether students have progress or development is the most important indicator to measure the effective teaching (John et al., 2017; Singh-Pillay and Sotsaka, 2017; Lawson et al., 2017).
\end{abstract}

To concern about the progress and development of students, the first thing is requiring teachers to have "object" consciousness. Teaching is not a singularity, leaving "learning", it does not matter "teaching", therefore, teachers must establish the student's dominant position, and establish the thinking of "all for the development of students" (Zhu, 2011). Secondly, it asked the teacher to have a "whole person" concept. Student development is a 


\section{Contribution of this paper to the literature}

- Emphasizing the importance of "effective teaching" theory, and specify the direction for the development of higher education.

- Getting deep study of the "effective teaching" theory to achieve the purpose of improving the level of higher education.

- Improving the "effective teaching" theory to enhance the integrity of the application in higher education.

comprehensive development, not a certain aspect or the development of a discipline. Teachers cannot estimate a too high value of their own teaching, but also not only the value of the discipline in the discipline, they should be located in a complete human development (Li, 2013). Concerned about teaching efficiency, it required teachers to have the concept of time and efficiency. Teachers in teaching cannot follow the feeling and simply think "efficiency" as "spend the least time to teach the most content." Teaching efficiency does not depend on how much content the teacher to teach, but depends on learning results and learning process of the students in unit time, which needs a sense of reflection for teachers (Kwon and Block, 2017; Collins and Staples, 2017).

\section{LITERATURE REVIEW}

Western higher education emphasizes teaching to achieve the desired teaching objectives, and using the effectiveness to evaluate the effectiveness of teaching. Medley defines effective teaching as a teacher in teaching activities that can motivate students to learn and improve to achieve the teaching goals (Fang and Cai, 2016; Yi et al., 2017). Balloentyne, Bain and Packer thought that effective teaching is successful to achieve the students are willing to learn and can do what they cannot do before teaching. Borich thought that effective teaching is the teacher's careful arrangement of five key teaching behaviors and five ancillary teaching behaviors, which were combined into meaningful rhythms and patterns to achieve teaching goals in the classroom. Schonwetter, Clifton and Raymond define effective teaching for teachers' behavior which can promote the students' academic achievement (Miao et al., 2014; Stoehr et al., 2017). This view is based on the development of students to define the effective teaching, that effective teaching can effectively achieve all aspects of student development, and promote the improvement of students' academic achievement. Koppi, Lublin and Chaloupka believe that effective teaching is to guide students to actively participate in the teaching of intellectual learning; effective teaching and learning can stimulate students' desire to learn, to promote students to actively grasp the knowledge, team work and problem-solving skills, and improve critical thinking ability and the establishment of lifelong learning attitude of teaching and learning (Li, 2011; Goren and Yemini, 2017). The above analysis can be considered that the "effective teaching" theory in the role of Western higher education is to help students better improve their learning ability, so as to build a more active learning atmosphere (Gregorius, 2017; Blonder and Sakhnini, 2017; LaChausse, 2017).

In China, the application of "effective teaching" theory in higher education generally can be summarized as follows: (1) effective teaching research in teaching theory and practice of research in the field of response is growing which plays a universal teaching of "New thinking" and leads to the further curriculum reform of higher education; (2) the research and questioning on the meaning and characteristics of effective teaching has never stopped, so far there are still many scholars with enthusiasm to explore, which showed that the academic community has not reached consensus in this regard. (3) Research on the characteristics of teachers and teaching behavior is the focus of effective teaching research. The research results have already begun to influence the research and practice of teachers' professional development and teacher training mode. (4) the research results on effective teaching strategies is large, and the effective teaching is becoming increasingly popular, which have widely affected the school teaching (Sun et al., 2010; Nwagu et al., 2017).

\section{METHODS}

The four indicators of student development and progress, teaching income, reflective teaching and innovative thinking are powerful factors that describe the application of "effective teaching" theory in higher education (Peng, 2010; Akre and Suris, 2017). In order to better describe the relationship between the four indicators, and then complete the "effective teaching" theory in the application of higher education analysis, the BBM principles was introduced to do the structural thinking of the four indicators. BBM principle is the extension of the pyramid model, the specific application of the principle is shown in Figure 1 (John et al., 2017). 


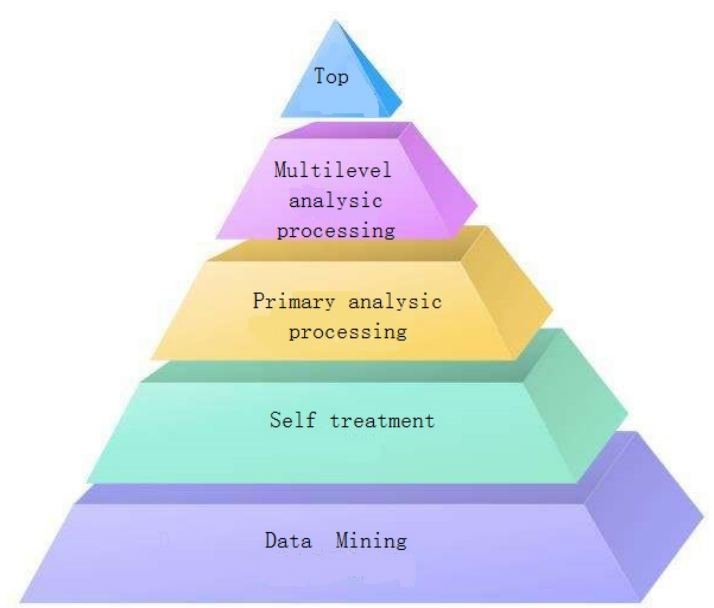

Figure 1. BBM application schematic

The five layers in the figure are data mining, self-treatment, primary analysis, multi-level analysis and top-level analysis. In this study, 100 university students were selected as the object of investigation, the development and progress of the students, the teaching income, the teaching progress, the students' Reflection of teaching, innovative thinking are the four indicators to be treated as variables. That is, the students' development and progress, teaching income, reflective teaching, innovative thinking are as self-treatment, primary analysis, multi-level analysis and top-level analysis. In each case, the application of "effective teaching" theory in higher education are analyzed, and each case of data mining are 100 university students (Gunter and Reeves, 2017; Judd and Elliott, 2017).

Set $\mathrm{A}$ as the data mining, B as self-treatment, $\mathrm{C}$ as the primary analysis, D as the multi-level analysis and $\mathrm{E}$ as the top-level analysis, the association between the layers can be expressed as follows:

$$
F(B \mid A)=\frac{P(B) P(A \cup B)}{\sum_{B=0}^{B} P(B) P(A \cup B)}
$$

where $F(B \mid A)$ represents the determination of self-treatment under the premise of satisfying data mining, $P(B)$ represents the probability of self-treatment, and $P(A \cup B)$ represents the probability of self-treatment under the premise of satisfying data mining. To determine the other layer indicators, just replaced the corresponding data in the corresponding parts (Costa and Miranda, 2017; Harris, 2017).

\section{RESULTS}

BBM principle is Applied to analyze the application of "effective teaching" theory in the higher education, the basic relationships between the indicators are as shown in Table 1.

Table 1. Analysis of the application of "Effective teaching" theory in higher education

\begin{tabular}{|c|c|c|}
\hline Arrangement & Index & Influence \\
\hline Data mining & 100 university students & The original index has no influence on the specific application. \\
\hline Self treatment & $\begin{array}{l}\text { The development and } \\
\text { progress of students }\end{array}$ & $\begin{array}{l}\text { The basic variable index has the main influence on the specific } \\
\text { application. }\end{array}$ \\
\hline Primary & Teaching gains & The primary variable index has a local influence on specific application. \\
\hline Multilevel analysis processing & Reflective teaching & Two variable indicators have secondary effects on specific applications. \\
\hline Top level analysis processin & Innovative thinking & $\begin{array}{l}\text { The influence of the following variable index on the specific application } \\
\text { is disturbed by other indexes. }\end{array}$ \\
\hline
\end{tabular}

where 100 university students as the original variable, and has no impact with the application of "effective teaching" theory in higher education. The rest of the indicators have different impact due to different levels. The application analysis of student development and progress as a self-treatment is shown as Figure 2. 


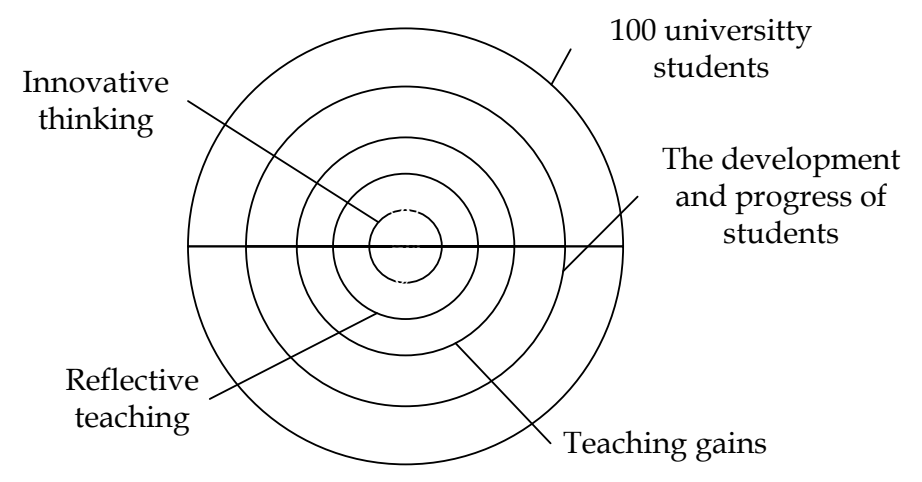

Figure 2. Application analysis of student development and progress as a self-treatment

where five rings are from inside to outside, followed by innovative thinking, reflective teaching, teaching income, student development and progress, and 100 university students. According to the trend of the circle between the above chart, we can find that the development of students and self for self-treatment, its own "effective teaching" theory in the application of higher education have a greater impact; the impact on other indicators are less than the development and progress of students. The application analysis of teaching income as self-treatment is shown as Figure 3.

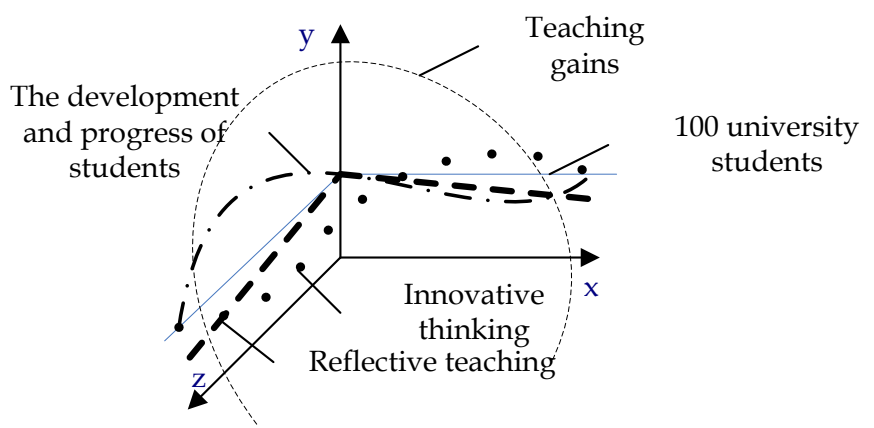

Figure 3. Application analysis of teaching income as self-treatment

According to the trend of the curve in the above chart, we can find that the other indicators have less influence on the application of the theory of "effective teaching" in higher education, except the teaching income. The application of "effective teaching" theory in higher education has a significant impact.

Analysis of Figure 4 showed that when the reflective teaching as a self-treatment, it has a significant impact on the application of "effective teaching" theory in higher education, while the other indicators have much lower impact. 


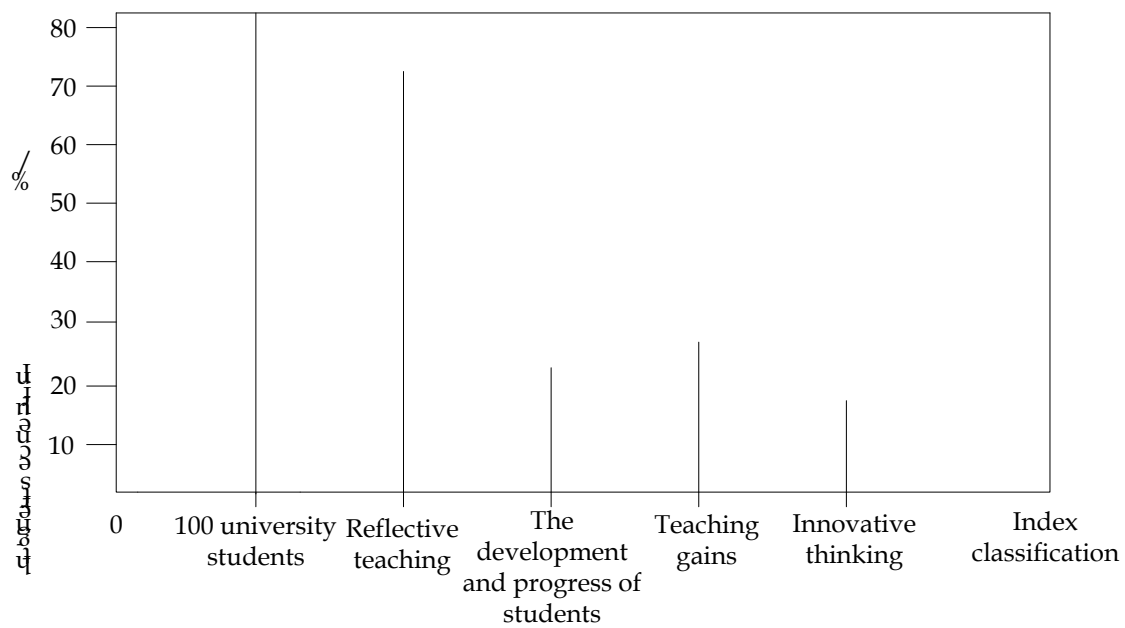

Figure 4. Application analysis of reflective teaching as self-treatment

The Figure 5 showed that when the innovative thinking as a self-treatment, it has a significant impact the application of "effective teaching" theory in higher education, and those of other indicators are too small to consider (Fan and Zhang, 2016).

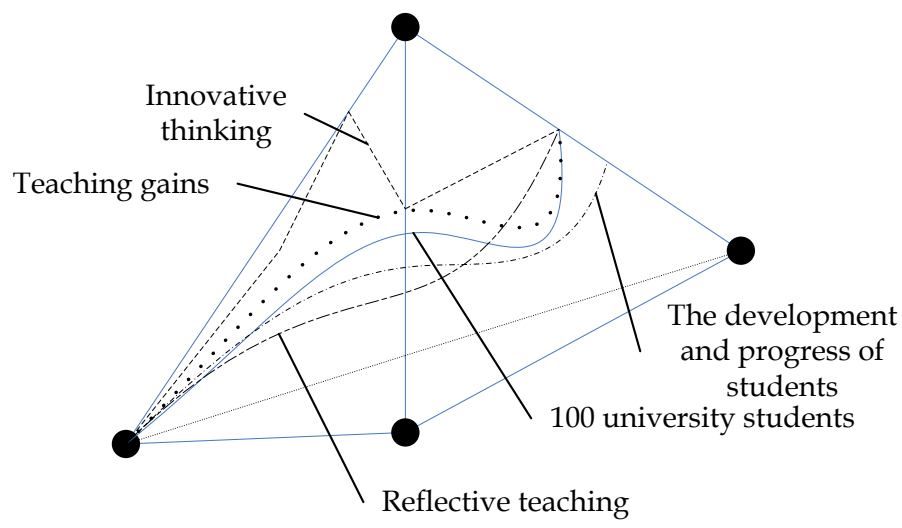

Figure 5. Application analysis of innovative thinking as self-treatment

\section{DISCUSSION}

Based on the influence of each indicator on the application, discuss the following four aspects:

(1) Students' development and progress as the self-treatment. Through the distribution of each ring in Figure 2, we can see that 100 university students as data mining and remained unchanged; students' development and progress as self-treatment has the main impact on the application; teaching income, reflective teaching and innovative thinking were as primary analysis, multi-level analysis and top-level analysis, which have very small impact on the application.

(2) Teaching income as the self-treatment. Through the trend of curve in Figure 3, we can see that 100 university students as data mining, and remained unchanged; teaching income was as the self-treatment, which has the main impact on the application; student development and progress, reflective teaching and innovative thinking were as primary analysis, multi-level analysis and top-level analysis, which have very small impact on the application.

(3) Reflective teaching as the self-treatment. Through the change of the straight line in Figure 4, we can see that 100 university students as data mining and remained unchanged; reflective teaching was as the selftreatment, which has the main impact on the application; student's development and progress, teaching income and innovative thinking were as primary analysis, multi-level analysis and top-level analysis, which have very small impact on the application. 
(4) Innovative thinking as the self-treatment. Through the trend of curve in Figure 5, we can see that 100 university students as data mining and remained unchanged; innovative thinking was as self-treatment, which has the main impact on the application; student development and progress, teaching income and reflective teaching were as primary analysis, multi-level analysis and top-level analysis, which have very small impact on the application.

\section{CONCLUSION}

Through the above research we can see that the "effective teaching" theory has four indicators of student development and progress, teaching income, reflective teaching, innovative thinking. Taking 100 university students as the object of investigation, the four indicators will have some influence on the application of "effective teaching" theory in higher education. But the four indicators will not have an impact on the application of the situation at the same time, only one is the main, the others are supplement, which impact are too weak to be negligible. Therefore, in order to strengthen the application of the theory of "effective teaching" in higher education, we should strengthen one of the four indicators under the premise of keeping the same of the other three.

\section{ACKNOWLEDGEMENT}

The question for study of project setup about "The Twelfth Five-Year Plan" of Education Scientific-China Hubei province (2014) "The Innovational exploration about teaching supervision system of Local Undergraduate Universities in transitional developing" (No. 2014B218).

\section{REFERENCES}

Akre, C., \& Suris, J. C. (2017). Adolescents and young adults' perceptions of electronic cigarettes as a gateway to smoking: a qualitative study in Switzerland. Health Education Research, 32(5), 448-454.

Blonder, R., \& Sakhnini, S. (2017). Finding the connections between a high-school chemistry curriculum and nanoscale science and technology. Chemistry Education Research and Practice, 18(4), 903-922.

Cobbinah, C., \& Bayaga, A. (2017). Physics content and pedagogical changes: ramification of theory and practice. EURASIA Journal of Mathematics, Science and Technology Education, 13(6), 1633-1651. doi:10.12973/eurasia.2017.00689a

Collins, K., \& Staples, K. (2017). The role of physical activity in improving physical fitness in children with intellectual and developmental disabilities. Research in Developmental Disabilities, 69, 49-60.

Costa, J. M., \& Miranda, G. L. (2017). Relation between Alice software and programming learning: A systematic review of the literature and meta-analysis. British Journal of Educational Technology, 48(6), 1464-1474. doi:10.1111/bjet.12496

Fan, J. L., \& Zhang, J. P. (2016). Analysis on the Factors Affecting the Effectiveness of Informatization Teaching in Secondary Vocational Schools. China Vocational and Technical Education, 14(9), 78-83.

Fang, D. S., \& Cai, Y. F. (2016). Sports health teaching theory research-Comment on "sports and health tutorial theory research". Chinese Journal of School Health, 37(09), 1442-1445.

Goren, H., \& Yemini, M. (2017). The global citizenship education gap: Teacher perceptions of the relationship between global citizenship education and students' socio-economic status. Teaching and Teacher Education, $67,9-22$.

Gregorius, R. M. (2017). Performance of underprepared students in traditional versus animation-based flippedclassroom settings. Chemistry Education Research and Practice, 18(4), 841-848.

Gunter, G. A., \& Reeves, J. L. (2017). Online professional development embedded with mobile learning: An examination of teachers' attitudes, engagement and dispositions. British Journal of Educational Technology, 48(6), 1305-1317. doi:10.1111/bjet.12490

Harris, J. C. (2017). Multiracial Campus Professionals' Experiences with Multiracial Microaggressions. Journal of College Student Development, 58(7), 1055-1073.

Jiang, L. B., \& Chen, Y. Q. (2016). A Study on the construction of open resources and the practice of the teaching of education curriculum - A case study on the construction of "Effective Teaching". Heilongjiang Researches on Higher Education, 32(08), 46-49.

John, A., \& Zapata Roblyer, M. (2017). Mothers Parenting a Child with Intellectual Disability in Urban India: An Application of the Stress and Resilience Framework. Intellectual and Developmental Disabilities, 55(5), 325-337. 
John, M., Molepo, J. M., \& Chirwa, M. (2017). South african learners' conceptual understanding about image formation by lenses. EURASIA Journal of Mathematics, Science and Technology Education, 13(6), 1723-1736. doi:10.12973/eurasia.2017.00694a

Judd, T., \& Elliott, K. (2017). Methods and frequency of sharing of learning resources by medical students. British Journal of Educational Technology, 48(6), 1345-1356. doi:10.1111/bjet.12481

Kwon, E. H., \& Block, M. E. (2017). Implementing the adapted physical education E-learning program into physical education teacher education program. Research in Developmental Disabilities, 69, 18-29.

LaChausse, R. G. (2017). A clustered randomized controlled trial to determine impacts of the Harvest of the Month program. Health Education Research, 32(5), 375-383.

Lawson, J. E., Cruz, R. A., \& Knollman, G. A. (2017). Increasing positive attitudes toward individuals with disabilities through community service learning. Research in Developmental Disabilities, 69, 1-7.

Li, B. (2011). Application of support vector machine in the evaluation of teaching quality in universities. Computer Simulation, 28(10), 402-405.

Li, G. G. (2013). China vocational and technical education institute and higher Education Press, a comprehensive cooperation agreement signed ceremony held in Beijing. China Vocational and Technical Education, 19(04), 2526.

Miao, Q., Yu, Z. Y., Hou, H. Q., et al. (2014). Application and discussion of multisim simulation software in high frequency electronic circuit teaching. Modern Electronics Technology, 37(20), 127-129.

Nwagu, E. N., Dibia, S. I. C., \& Odo, A. N. (2017). Socio-cultural norms and roles in the use and abuse of alcohol among members of a rural community in Southeast Nigeria. Health education research, 32(5), 423-436.

Peng, C. X. (2010). Improvement of "Effective Teaching" in Specialized Classroom - Investigation Report on "Effective Teaching" of Specialized Class in Jiang'an District of Wuhan City. China Vocational and Technical Education, 7(14), 38-42.

Singh-Pillay, A., \& Sotsaka, D. S. (2017). Engineering graphics and design teachers' understanding and teaching of assembly drawing. EURASIA Journal of Mathematics, Science and Technology Education, 13(5), 1213-1228. doi:10.12973/eurasia.2017.00668a

Stoehr, A., Benders, T., van Hell, J. G., \& Fikkert, P. (2017). Second language attainment and first language attrition: The case of VOT in immersed Dutch-German late bilinguals. Second Language Research, 33(4), 483-518.

Sun, X. L., Wang, N., \& Liang, Y. (2010). Application of BP neural network teaching evaluation model and simulation. Computer Simulation, 27(11), 314-318.

Wang, J., \& Zhao, G. S. (2016). Exploration of problem-based teaching model in graduate teaching-Taking "information system security engineering" teaching reform as an example. Heilongjiang Researches on Higher Education, 32(11), 91-94.

Yi, W., Lu, S., \& Ma, G. (2017). Frequency, contingency and online processing of multiword sequences: An eyetracking study. Second Language Research, 33(4), 519-549.

Zhu, Y. M. (2011). Art design professional "studio" mode of teaching quality monitoring system-Zhejiang Vocational and Technical University as an example. Heilongiiang Researches on Higher Education, 17(06), 161163.

\section{http://www.ejmste.com}

